\title{
Visual discrimination behavior in galago and owl monkey ${ }^{1}$
}

\author{
ANNETTE EHRLICH, REGIONAL PRIMATE RESEARCH CENTER, UNIVERSITY OF WASHINGTON \\ WILLIAM H. CALVIN, DEPARTMENT OF NEUROSURGERY, UNIVERSITY OF WASHINGTON
}

Two nocturnal primates, galago and owl monkey, were inferior to rhesus monkeys in ability to detect small differences in brightness. Neither was able to learn a red-green discrimination. Although galagos did somewhat better than owl monkeys on pattern discriminations, both species were inferior to rhesus monkeys.

This report deals with the ability of two nocturnal animals, the South American owl monkey (Aotes trivirgatus) and the African greater galago (Galago crassicaudatus), to learn visual discriminations based on differences in brightness, color, and pattern. The performance of these relatively primitive members of the primate order is compared with that of a higher primate, the rhesus monkey.

Method

Ss were two galagos, four owl monkeys (two of which died before the tests had been completed), and two rhesus monkeys. All of the animals were young, adult males. Only the owl monkeys were wildborn. Mean weights at the start of the experiment were: rhesus monkeys-1800 g; galagos-900 g; owl monkeys $-750 \mathrm{~g}$.

Apparatus consisted of a test cage, $14 \times 10 \times 10 \mathrm{in}$. high, with a two-choice visual discrimination panel on one wall. Visual stimuli were presented by means of multiple stimulus projectors, containing 12 small light bulbs (GE No. 1813) mounted on the back of the panel. The apertures through which the animal viewed the stimuli were $1-1 / 4 \mathrm{in}$. in diameter, and they were separated by 7 in., cepter to center. Threequarters of an inch beneath each aperture was a lever that could be depressed by a force. of $30 \mathrm{~g}$. The animal indicated its choice by pressing the lever beneath the appropriate stimulus. Programming of stimuli and recording of responses were carried out automatically.

Animals were on a 24-h food deprivation schedule and they received a single test session, consisting of 200 trials, each day. Reward consisted of $190 \mathrm{mg}$ banana-flavored pellets. All testing was done in a darkened, sound-deadened chamber. Stimuli to be discriminated were presented simultaneously and they remained visible indefinitely until the animal responded, but each response was followed by a 7-sec intertrial delay. A noncorrection procedure was used, and the correct stimulus shifted randomly from side to side. However, if the animal pressed the same lever more than four times in succession, the correct stimulus appeared on the opposite side on the next trial and continued to appear there until the animal had made two successive presses on that side. In this way, the formation of position habits was discouraged. The learning criterion was $45 / 50$ correct in any one quarter of the 200-trial test session. Trials on a particular problem were discontinued if the animal completed 2000 trials without meeting criterion.

During the preliminary training, the animal learned to press at a panel that contained only one lever, but the two-choice panel was substituted as soon as the bar pressing habit had been acquired. Food could then be obtained by pressing either lever and both panels were identically illuminated. Training was continued until the animal had recelved approximately 50 reinforcements on each lever. For an animal that did not alternate spontaneously from one lever to the other, reinforcement was made available only if the nonpreferred lever was pressed, and thus spontaneous side preferences were readily eliminated before the discrimination trials began.

Brightness Discrimination with white lights. Ten problems of increasing difficulty were given. On the first, the animals had to discriminate between- light and no light but, on subsequent problems, the correct stimulus was always the brighter of two lights. This stimulus remained unchanged throughout the series, and the brightness of the incorrect stimulus was varied by means of Wratten neutral density filters. The $\log$ values of the filters are shown in Fig. 1, along with the estimated percentages of light transmitted. If the animal falled to meet criterion on any discrimination in this series, succeeding problems were not run.

Color Discrimination. This was a red-green discrimination on which red was correct. Neutral density filters were used to alter the brightness of the six individual bulbs in each projector. In addition, the number of bulbs lit behind each colored stimulus on a single trial varied between one and six; in this way, brightness was made to vary over a sufficiently wide range (2.5 log units) that it could not serve as a learning cue.

Pattern Discrimination. Three problems were presented and the stimuli are shown in Fig. 2. Stimuli were outlined in white on a black background and each was lit by a single bulb.

\section{Results and Discussion}

Brightness. Figure 1 lists incorrect stimuli and trials to criterion for each of the 10 problems in 


\begin{tabular}{|c|c|c|c|c|c|c|c|c|c|}
\hline \multicolumn{10}{|c|}{ TRIALS TO CRITERION } \\
\hline $\begin{array}{c}\text { Log Value of } \\
\text { Incorrect } \\
\text { Stimulus }\end{array}$ & $\begin{array}{c}\text { Percent } \\
\text { Light } \\
\text { Transmitted }\end{array}$ & & $\begin{array}{c}\text { esus } \\
\text { Cheys } \\
\text { C }\end{array}$ & $\mathrm{J}$ & $\begin{array}{l}\text { Or } \\
\text { Mon } \\
\text { Sa }\end{array}$ & $\begin{array}{l}\text { wi } \\
\text { keys } \\
\text { So }\end{array}$ & $\mathrm{Se}$ & & $\begin{array}{r}\text { lagos } \\
\text { A. }\end{array}$ \\
\hline no light & 0.0 & 200 & 200 & 468 & 699 & 119 & 380 & 400 & 531 \\
\hline 2.5 & 10 & 589 & 150 & 428 & 243 & 107 & 697 & 791 & 296 \\
\hline 1.8 & 3.0 & 50 & 50 & 434 & 537 & 179 & 150 & 50 & 50 \\
\hline 14 & 40 & 50 & 50 & $F_{*}^{*}$ & 1052 & 446 & 989 & 406 & 585 \\
\hline 09 & 125 & 100 & 50 & & 461 & 681 & 403 & 338 & 200 \\
\hline 07 & 200 & 150 & 174 & & 200 & 169 & $F^{*}$ & 1408 & 539 \\
\hline 0.5 & 350 & 50 & 50 & & $F^{*}$ & 264 & & $F^{*}$ & $F^{*}$ \\
\hline 03 & 500 & 100 & 100 & & & 602 & & & \\
\hline 0.2 & 670 & 1400 & 244 & & & $F^{*}$ & & & \\
\hline 0.1 & 83.0 & 300 & 725 & & & & & & \\
\hline
\end{tabular}

Fig. 1. Brightness discrimination series.

the series. All three species learned to make brightness discriminations, but they differed with respect to how different the stimuli had to be for learning to occur. Only the two rhesus monkeys learned the full set of problems. Of the lower primates, only one, an owl monkey, approached the performance of the rhesus monkeys. This animal failed on the ninth problem, but the other owl monkeys failed on the fourth, sixth, and seventh problems, respectively. Both galagos failed on the seventh problem. Silver (1966) has reported that, in a situation in which the animal had to detect the position of a single light, the threshold sensitivity of a single galago $S$ was approximately equal to that of a human. However, it would appear from the present data that the ability of this species to discriminate brightness difference does not equal that of the rhesus monkey, although it is similar to that of another nocturnal primate, the owl monkey.

Color. Only the two rhesus monkeys learned the red-green discrimination, and they did so in 100 and 200 trials, respectively. Neither the galagos nor the owl monkeys learned the red-green discrimination within the 2000-trial limit. At the time the experiment was initiated, there was a question of whether the owl monkey possessed a few cones in an otherwise all-rod retina (see Jones, 1965, for a review), and it therefore seemed pertinent to look for behavioral evidence of color vision. Subsequently, two papers by Jones appeared which are relevant to this point. In one study (Jones, 1965), no cones were detected by light microscopy. In the second (Jones, 1966), physiological evidence for more than one receptor type was found in the spectral sensitivity of neurons in the lateral geniculate nucleus. However, because these spectral sensitivity curves were broad compared to those of monkeys known to possess color vision, Jones concluded that the owl monkey may be a monochromat nonetheless. The present

\begin{tabular}{|c|c|c|c|}
\hline \multirow{6}{*}{ 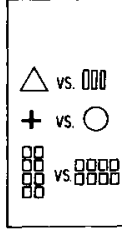 } & Rhesus & Owl monixeys & Gologos \\
\hline & N. C & J. So & $P \quad A$ \\
\hline & $100 \quad 100$ & $1471 \quad 270$ & 374500 \\
\hline & $100 \quad 100$ & $1519 \quad 444$ & 383300 \\
\hline & $250 \quad 100$ & $F^{*} \quad \underline{646}$ & $565 \quad 234$ \\
\hline & $450 \quad 300$ & $4990 \quad 1360$ & $1322 \quad 1034$ \\
\hline \multicolumn{4}{|l|}{ ERRORS } \\
\hline$\triangle$ vs. & 10 & 713 & $96 \quad 239$ \\
\hline+ vs. $\bigcirc$ & 14 & $505 \quad 127$ & $137 \quad 105$ \\
\hline 骂 vs㗊嚾 & 50 & 606 & 165 \\
\hline & 80 & $1824 \quad 302$ & $398 \quad 371$ \\
\hline
\end{tabular}

Fig. 2. Pattern discrimination series.

findings, then, add behavioral support to such arguments. Similarly, the inability of the galagos to learn the red-green discrimination is in accord with recent anatomical and electrophysiological evidence that this species, too, lacks color receptors (Dartnall et al, 1965).

Pattern. Figure 2 shows trials to criterion and errors on the three pattern discrimination problems. Although they took longer and made more errors than the rhesus monkeys, both galagos and one of the two surviving owl monkeys learned the three discriminations. The behavior of the galagos is of special interest because they, along with other prosimians, are considered poor learners. Jolly (1964), for example, was unable to overcome persistent position habits in an experiment on object discrimination learning in prosimians. Yet, as the present results show, with appropriate training procedures galagos learn complex visual discriminations readily. They may, in fact, be superior to owl monkeys in this regard, although further work would be needed to establish this point.

\section{References}

DARTNALL, H. J. A., ARDEN, G. B., IKEDA, H., LUCK, C. P., ROSENBERG, M. E., PEDLER, C. M. H., \& TANSLEY, K. Anatomical, electrophysiological and pigmentary aspects of vision in the bushbaby: An interpretative study. Vis. Res., 1965, 5, 399-424. JOLLY, A. Choice of cue in prosimian learning. Anim. Behav., 1964, 12, 571-577.

JONES, A. E. The retinal structure of the owl menkey (Aotes trivirgatus). J. comp. Neurol., 1965, 125, 19-28.

JONES, A. E. Wavelength and intensity effects on the response of single lateral geniculate nucleus units in the owl monkey. J. Neurophysiol., 1966, 29, 125-138.

SILVER, P. H. Spectral sensitivity of a trained busin baby. Vis. Res., $1966,6,153-162$.

Note

1. This investigation was supported by Public Health Service Grant No. FR 00166 from the National Institutes of Health. Present address of first author: Bowling Green State University. 